\title{
$\mathrm{BSCCO}$ 플라즈마 용사피막의 부분용융열처리 후 어닐링 시간에 따른 초전도 특성
}

\author{
박정식 ${ }^{1} \cdot$ 이선홍 $^{2} \cdot$ 박경채 $^{3 \dagger}$ \\ ${ }^{1}$ 대구보건대학교 안경광학과, ${ }^{2}$ 삼성SDI 중앙연구소 기반기술랩, ${ }^{3}$ 경북대학교 금속신소재공학과
}

\section{Characteristics of Plasma Sprayed BSCCO Superconductor Coatings with Annealing Time After Partial Melt Process}

\author{
Jeong-Sik Park ${ }^{1}$, Seon-Hong Lee ${ }^{2}$ and Kyeung-Chae Park ${ }^{3 \dagger}$ \\ ${ }^{1}$ Department of Ophthalmic Optics, Daegu Health College, Daegu 702-722, Korea \\ ${ }^{2}$ Corporate R\&D Center, Samsung SDI Co. Ltd., Yongin 446-577, Korea \\ ${ }^{3}$ Department of Materials Science and Metallurgy, Kyungpook National University, Daegu 702-701, Korea
}

(2014년 1월 10일 접수 : 2014년 2월 21일 최종수정 : 2014년 2월 21일 채택)

\begin{abstract}
Bi}_{2} \mathrm{Sr}_{2} \mathrm{CaCu}_{2} \mathrm{O}_{\mathrm{x}}(\mathrm{Bi}-2212)$ and $\mathrm{Bi}_{2} \mathrm{Sr}_{2} \mathrm{Ca}_{2} \mathrm{Cu}_{3} \mathrm{O}_{\mathrm{y}}(\mathrm{Bi}-2223)$ high- $\mathrm{T}_{\mathrm{c}}$ superconductors(HTS) have been manufactured by plasma spraying, partial melt process(PMP) and annealing treatment(AT). A Bi-2212/2223 HTS coating layer was synthesized through the peritectic reaction between a 0212 oxide coating layer and 2001 oxide coating layer by the PMP-AT process. The 2212 HTS layer consists of whiskers grown in the diffusion direction. The Bi-2223 phase and secondary phase in the Bi-2212 layer were observed. The secondary phase was distributed uniformly over the whole layer. As annealing time goes on, the Bi2212 phase decreases with mis-orientation and irregular shape, but the Bi-2223 phase increases because a new Bi-2223 phase is formed inside the pre-existing Bi-2212 crystals, and because of the nucleation of a Bi-2223 phase at the edge of Bi-2212 crystals by diffusion of $\mathrm{Ca}$ and $\mathrm{Cu}-\mathrm{O}$ bilayers. In this study the spray coated layer showed superconducting transitions with an onset $\mathrm{T}_{\mathrm{c}}$ of about both $115 \mathrm{~K}$, and $50 \mathrm{~K}$. There were two steps. Step 1 at $115 \mathrm{~K}$ is due to the diamagnetism of the Bi2223 phase and step 2 at $50 \mathrm{~K}$ is due to the diamagnetism of the Bi-2212 phase.
\end{abstract}

Key words plasma spray, BSCCO superconductor, PMP(partial melt process), Bi-2212/2223 phase, annealing time.

\section{1. 서 론}

1911년 네델란드 과학자 온네스(Onnes)에 의해 처음으 로 초전도 현상(superconductivity)이 발견된 이래 초전도 체에 대한 이해와 응용을 위해 다양한 이론과 연구개발 이 이루어져 왔다. 특히 Maeda 등이 발견한 $\mathrm{Bi}$-계 고 온초전도체 ${ }^{1-2)}$ 는 $\mathrm{Bi}_{2} \mathrm{Sr}_{2} \mathrm{Ca}_{\mathrm{n}-1} \mathrm{Cu}_{\mathrm{n}} \mathrm{O}_{\mathrm{x}}$ 로 표시되며, $\mathrm{n}=1$ 일 때 $\mathrm{Tc}$ (citical temperature, 임계온도)가 $20 \mathrm{~K}$ 의 $\mathrm{Bi}_{2} \mathrm{Sr}_{2} \mathrm{CuO}_{\mathrm{x}}$

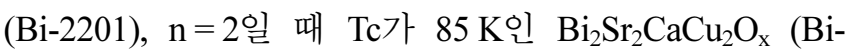
2212 ), 그리고 $\mathrm{n}=3$ 일 때 $\mathrm{Tc}$ 가 $110 \mathrm{~K}$ 인 $\mathrm{Bi}_{2} \mathrm{Sr}_{2} \mathrm{Ca}_{2} \mathrm{Cu}_{3} \mathrm{O}_{\mathrm{x}}$ (Bi-2223)의 세 가지 상으로 크게 구분된다. 이들 중 $\mathrm{Bi}-$
2212상(약 $78 \mathrm{~K}$ )은 $\mathrm{Bi}-2223$ 상(약 $110 \mathrm{~K}$ )에 비해 $\mathrm{Tc}$ 는 낮 지만 임계전류밀도가 큰 것으로 알려져 있다. 그러나 $\mathrm{BSCCO}$ 계를 포함한 이들 고온초전도체는 대부분 산화물 로 이루어져 있어 저온초전도체와 비교하여 다양한 형 상으로 제조할 수 없다는 큰 약점을 가지고 있다. 산화 물은 금속에 비해 연성이나 소성이 매우 낮아 기계적인 성질이 약해 선재나 코일로 제작하는 것이 어렵다. 또 한 고온초전도체는 다성분계의 산화물로 화학조성의 불 균일성 또는 산소의 결손 등 초전도 성능을 저하시킬 수 있는 다용한 요소가 있다.

이와 같은 이유로 일반적으로 기존의 산화물 고온초전

\footnotetext{
${ }^{\dagger}$ Corresponding author

E-Mail : kcpark@knu.ac.kr (K.-C. Park, Kyungpook Nat'l Univ)
}

(C) Materials Research Society of Korea, All rights reserved.

This is an Open-Access article distributed under the terms of the Creative Commons Attribution Non-Commercial License (http://creativecommons.org/licenses/by-nc/3.0) which permits unrestricted non-commercial use, distribution, and reproduction in any medium, provided the original work is properly cited. 
도 제조는 주로 $\mathrm{Ag}$ 파이프 안에 산화물을 충진시킨 후 인발 및 소결하여 제조하는 PIT 법 ${ }^{3-4)}$ 이 많이 사용되어 왔다. 그러나 이 공정은 인발 및 소결 시 초전도 산화 물의 손상 및 수축변형으로 인해 초전도 특성이 매우 저 하되는 단점이 있다. 이러한 단점을 보완하기 위해 복 합 산화물 분말을 용사 코팅하여 박막형태로 제조하는 방법이 시도되고 있다.

특히 $\mathrm{BSCCO}$ 계의 초전도상인 $\mathrm{Bi}-2201,2212,2223$ 산화물은 고 융점의 $\mathrm{Sr}$-기지 산화물 기판과 저 융점의 $\mathrm{Bi}$-기지 산화물 코팅층 사이의 확산반응을 통해 형성된 다. ${ }^{5-6)}$ 그 중에서도 다른 초전도 상에 비해 균일한 $\mathrm{Bi}-$ 2212상을 생성하는 확산커플 제조에 있어서 최상의 조성 적 배합은 0212 피막 층과 2001 피막 층이다. 두껍고 균 일한 조성의 Bi-2212층은 2001/0212의 확산쌍(diffusion couple)에서 형성되는데 이러한 확산공정은 일반적인 소 결공정을 통한 방법보다 짧은 시간 내에 초전도상을 형 성한다.

본 연구에서는 2001/0212 이중층을 이용한 초전도체의 형성을 위해 이제까지의 $\mathrm{BSCCO}$ 초전도체 제조방법과는 달리 산화물초전도체의 가공에서 가장 큰 단점인 취성을 극복하고 신속한 초전도체의 형성을 위해 플라즈마 용사 를 이용하여 이중층을 만들고자 하였다. 이들 이중층의 용사피막 형성을 위해서는 2001 및 0212의 조성을 가지 는 용사분말의 제작하여 용사피막을 형성하였다. 그리고 형성된 용사피막에 대하여 PMP(partial melting process)$\mathrm{AT}$ (annealing treatment) ${ }^{7-8)}$ 를 이용하여 초전도 용사피막 을 형성하고, 이에 따라 생성된 Bi-2212/2223상에 대한 초전도 특성을 조사하고 미세조직, 상 및 성분분석을 통 하여 이들 초전도 상의 생성에 대해 검토하고자 하였다.

\section{2. 실험 방법}

본 연구에서는 플라즈마 용사 Bi-2212/2223 초전도피 막을 다층 용사피막으로 제작하였다. $0212(\mathrm{Sr}: \mathrm{Ca}: \mathrm{Cu}=$ $2: 1: 2)$ 용사피막 위에 $2001(\mathrm{Bi}: \mathrm{Cu}=2: 1)$ 용사피막 순서 로(이하 0212,2001 라 각각 칭함) 제조하였다.

$\mathrm{Bi}_{2} \mathrm{O}_{3}$ 분말과 $\mathrm{SrCO}_{3}$ 분말, $\mathrm{CaCO}_{3}$ 분말, $\mathrm{CuO}$ 분말은 분말 전문 제조회사인 Aldrich(USA) 제품을 사용하였다. $\mathrm{Bi}_{2} \mathrm{O}_{3}$ 분말은 5 10 $\mu \mathrm{m}$ 의 입도를 가지고 있고, $\mathrm{SrCO}_{3}$ 와 $\mathrm{CaCO}_{3}$ 는 $10 \sim 15 \mu \mathrm{m}, \mathrm{CuO}$ 분말은 $5 \sim 15 \mu \mathrm{m}$ 의 입도를 가지고 있 다. 모든 원료 분말의 순도는 $99.9 \%$ 이상이다. 2001와 0212 복합분말은 원자비로 각각 $\mathrm{Bi}: \mathrm{Cu}=2: 1, \mathrm{Sr}: \mathrm{Ca}: \mathrm{Cu}=$ 2:1:2로 칭량하고 이때 $\mathrm{SrCO}_{3}, \mathrm{CaCO}_{3}$ 내의 탄소를 제거 하기 위해 $850^{\circ} \mathrm{C}$ 에서 12 시간 하소하였다. 초전도피막의 재료로 쓰일 복합 분말의 조성과 크기를 Table 1에 나 타내었고, 복합 분말의 제조시 성분들의 균일한 분포를
Table 1. Compositions and powder sizes of spray powders for each coating layer.

\begin{tabular}{cccc}
\hline Layers & Materials & Size $(\mu \mathrm{m})$ & Elem. ratio(at\%) \\
\hline \multirow{2}{*}{2001} & $\mathrm{Bi}_{2} \mathrm{O}_{3}$ & $5-10$ & \multirow{2}{*}{$\mathrm{Bi}: \mathrm{Cu}=2: 1$} \\
& $\mathrm{CuO}$ & $5-15$ & \\
& $\mathrm{SrCO}_{3}$ & $10-15$ & \\
0212 & $\mathrm{CaCO}_{3}$ & $10-15$ & Sr;Ca;Cu=2:1:2 \\
& $\mathrm{CuO}$ & $5-15$ & \\
\hline
\end{tabular}

Table 2. Conditions of ball milling.

\begin{tabular}{cc}
\hline milling receptacle & stainless steel (SUS304) \\
milling media & stainless steel ball(SUS304) $\phi 12.5 \mathrm{~mm}$ \\
ball : powder & $10: 1$ (mass ratio) \\
revolution speed & $60 \mathrm{rpm}$ \\
atmosphere & air \\
milling time & $10-50 \mathrm{hr}$ \\
binder & polyvinyl alcohol \\
\hline
\end{tabular}

Table 3. Conditions of atmospheric plasma spray.

\begin{tabular}{cc} 
Coating layer & $2001 / 0212$ \\
Spray gun & METCO 9MB \\
Ar gas flow $(l / \mathrm{min})$ & 38 \\
Spray distance $(\mathrm{mm})$ & 90 \\
Spray angle & 90 \\
Arc current & 500 \\
Arc voltage & 50 \\
Powder feed rate $(\mathrm{g} / \mathrm{min})$ & 30 \\
Carrier gas flow rate $(l / \mathrm{min})$ & 8 \\
Coating thickness $(\mu \mathrm{m})$ & 200 \\
\hline
\end{tabular}

위하여 볼밀을 이용하여 Table 2와 조건으로 합금화 과 정을 실시하였다. 최종적으로 생산된 복합용사분말은 분 급하여 30 90 $\mu \mathrm{m}$ 의 입도를 가지는 분말을 사용하였다.

용사피막의 제조는 플라즈마 용사 건 $(9 \mathrm{MB}, \mathrm{METCO}$, USA)을 사용하여 Table 3 의 조건으로 대기 중에서 실 시하였다. 화염 발생 가스로 수소와 아르곤을 사용하였 고, 플라즈마 발생 가스로 1 차 가스인 아르곤을 사용하 였다. 플라즈마 용사에서 2001 및 0212 피막은 모두 같 은 조건을 적용하여 각각 약 $200 \mu \mathrm{m}$ 두께로 용사하였다. 2001 코팅 층과 0212 코팅 층간의 확산반응을 통한 $\mathrm{Bi}-2212 / 2223$ 초전도상의 형성하기 위하여 용사 후 2001/ 0212 피막을 PMP(Partial Melt Process)- AT(Annealing Treatment)를 Fig. 1과 같이 하였다. 우선, 로내 온도 $25^{\circ} \mathrm{C}$ 에서 최고온도인 $895^{\circ} \mathrm{C}$ 까지 약 $4{ }^{\circ} \mathrm{C} / \mathrm{min}$ 의 속도로 높여 1 시간 동안 대기 중에서 유지(PMP)한 다음 $\mathrm{AT}$ 온 도인 $850{ }^{\circ} \mathrm{C}$ 까지 약 $30^{\circ} \mathrm{C} / \mathrm{h}$ 의 냉각속도로 낮춘다. 이때 $\mathrm{AT}$ 시간에 따른 $\mathrm{Bi}-2212 / 2223$ 초전도 상의 성장거동을 조 


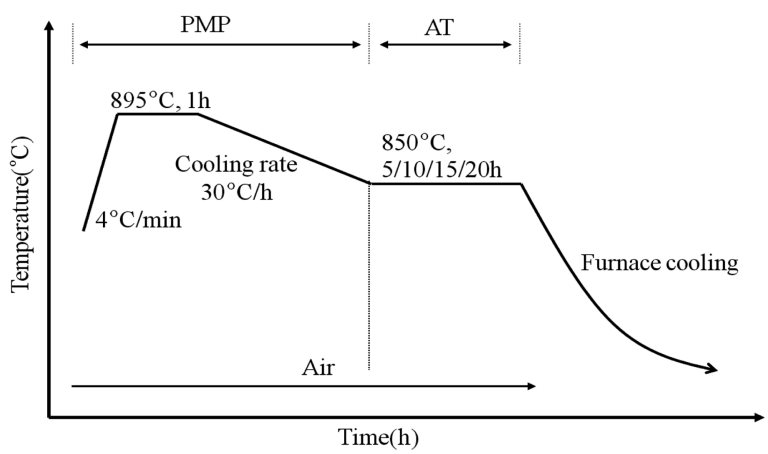

Fig. 1. PMP-AT schedule for the plasma sprayed coatings.

사하기 위해 각각 $850^{\circ} \mathrm{C}$ 에서 $5,10,15,20$ 시간동안 유지 후, $25^{\circ} \mathrm{C}$ 까지 대기 중에서 서냉하였다.

용사피막의 미세조직 관찰은 용사를 한 다음 PMP-AT 전/후 형성된 피막 표면 및 절단면의 형상을 보기 위해 표면 및 단면을 관찰하였고 PMP-AT 후 Bi-2212/2223 초전도 상의 미세조직의 변화를 조사하였다. 그리고 초 전도피막의 성분분포를 확인하기 위해 $\mathrm{EDS}$ 면 분석 및 점 분석을 하였다.

플라즈마 용사에 의한 초전도피막의 생성 상(Bi-2212/ 2223)의 분율을 조사하고 PMP-AT 조건에 의한 생성상 의 변화를 알아보기 위해 XRD(D/Max-IC, Rigaku), SEM (S-4300, Hitachi) 및 $\mathrm{EDS}(\mathrm{S}-2500 \mathrm{C}$, Hitachi) 분석을 하 였다.

플라즈마 용사 Bi-2212/2223 초전도피막의 초전도 특성

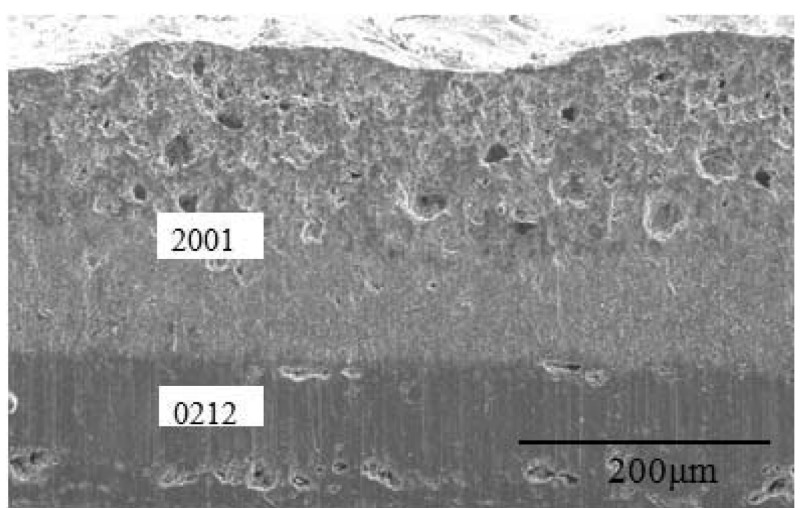

Fig. 2. The cross-sectional SEM images of the spray coating layer at $0 \mathrm{~h}$ AT.

은 MPMS(Magnetic Property Measurement System, 자 기특성측정시스템)를 이용하여 측정하였다. ZFC(Zero Field Cooling: $0 \mathrm{Oe}$ ) 조건 하에 모멘트를 측정하고 임계온도 를 조사하였다.

\section{3. 결과 및 고찰}

\section{1 어닐링처리(AT) 시간에 따른 $\mathrm{Bi}-2212 / 2223$ 상의 변화}

$\mathrm{AT}$ 시간을 변수 $(5,10,15,20$ 시간)로 하고 PMP-AT를 대기 중에서 실시한 경우 연구결과를 언급한다.

Fig. 2는 대기분위기에서 PMP 후 용사 코팅층의 단
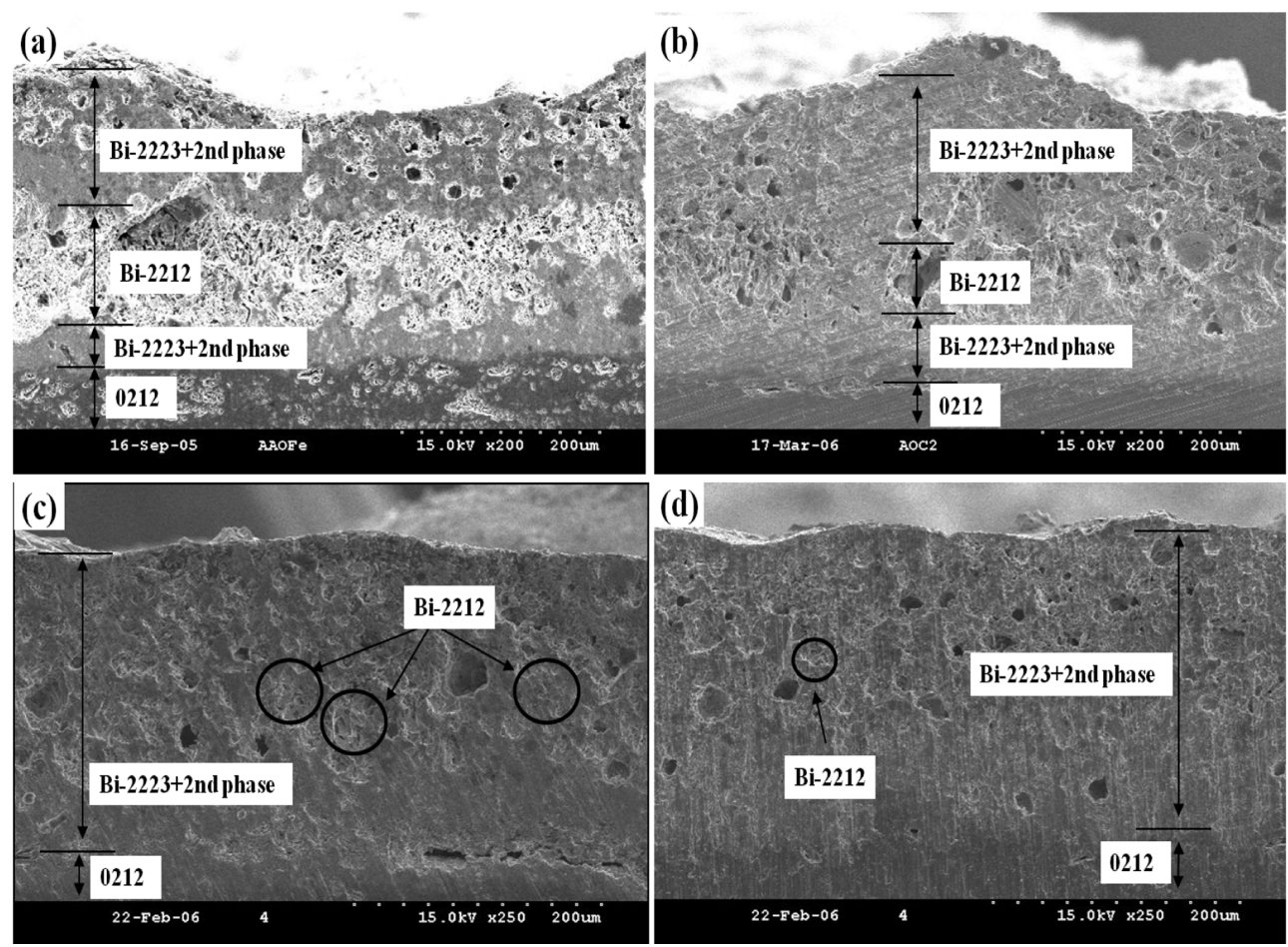

Fig. 3. SEM micrographs of Bi-2212/2223 coatings at various AT times. (a) 5h, (b) $10 \mathrm{~h}$, (c) $15 \mathrm{~h}$ and (d) $20 \mathrm{~h}$. 
면을 나타낸 것으로 2001층의 상부보다는 하부가 훨씬 치밀한 조직을 보이고 있다. 이는 $\mathrm{PMP}$ 과정에서 $\mathrm{Bi}$ 산 화물의 부분용융 및 아래쪽으로의 침강에 의한 것으로 판단된다.

Fig. 3은 AT 시간에 따른 Bi-2212/2223 코팅 층의 단 면을 나타내고 있다. (a)는 AT 5시간의 단면 조직으로 0212 층 위에 $\mathrm{Bi}-2223$ 상이 $30-40 \mu \mathrm{m}$ 의 층을 보이고 있으 며 그 위에 $\mathrm{Bi}-2212$ 상 휘스커가 $100 \mu \mathrm{m}$ 의 층을 형성하고 그 위에 Bi-2223상이 $100-110 \mu \mathrm{m}$ 의 층을 보이고 있다. ${ }^{9)}$ (b)는 AT 10 시간에서의 단면 조직으로 0212 층 위에 $\mathrm{Bi}-$ 2223상이 50-55 $\mu \mathrm{m}$ 의 층을 보이고 있으며 그 위에 $\mathrm{Bi}-$ 2212상 휘스커가 45-50 $\mu \mathrm{m}$ 의 층을 형성하고 그 위에 $\mathrm{Bi}-2223$ 상이 $140-150 \mu \mathrm{m}$ 의 층을 보이고 있다. (c)는 $\mathrm{AT}$ 15 시간에서의 단면 조직으로 0212 층 위에 전체적으로 $\mathrm{Bi}-$ 2223상이 층을 이루고 있으며 Bi-2212상 휘스커가 부분 적으로 층 내부에 형성되어 있다. (d)는 AT 20시간의 단 면 조직으로 $\mathrm{Bi}-2223$ 내에 $\mathrm{Bi}-2212$ 상 휘스커가 약간 존 재했다. 따라서 $\mathrm{AT}$ 의 시간이 지남에 따라 $\mathrm{Bi}-2223$ 상은
증가하고 $\mathrm{Bi}-2212$ 층의 휘스커는 점차 소멸해가는 것을 확 인할 수 있다.

2001층의 $\mathrm{Bi}, \mathrm{Cu}$ 성분은 0212층으로 부분 용융되어 확 산되는 반면, 0212 층의 $\mathrm{Sr}, \mathrm{Ca}, \mathrm{Cu}$ 는 2001층으로 확산된 다. 그 결과 Bi-2212상 휘스커가 먼저 생성하고 이후 $\mathrm{AT}$ 시간이 경과함에 따라 확산이 더욱 진행되어 주로 $\mathrm{Bi}-$ 2223상이 되고 제 2상 그리고 일부 $\mathrm{Bi}-2212$ 의 잔존이 확인되었다.

Fig. 4는 20시간 AT한 용사피막의 절단면을 $\mathrm{EDS}$ 로 성 분 $(\mathrm{Bi}, \mathrm{Sr}, \mathrm{Ca}, \mathrm{Cu})$ 분석한 결과이다. 2001 층의 $\mathrm{Bi}, \mathrm{Cu}$ 성 분은 0212 방향으로 부분 용융되어 확산되었고, 0212 층의 $\mathrm{Sr}, \mathrm{Ca}, \mathrm{Cu}$ 는 2001방향으로 상호 확산된다. 그 결과 $\mathrm{Bi}-$ 2212상 휘스커가 먼저 생성하고 이후 $\mathrm{AT}$ 시간이 경과함 에 따라 확산 층은 그림 (b)와 같이 주로 $\mathrm{Bi}-2223$ 과 $\mathrm{Bi}$ 성분이 없는(Bi-free) 제 2상 그리고 일부 $\mathrm{Bi}-2212$ 가 확 인된다.

Fig. 5는 AT 시간에 따른 $\mathrm{Bi}-2212$ 상과 $\mathrm{Bi}-2223$ 상의 미세조직을 나타냈다. $\mathrm{Bi}-2212$ 상이 $\mathrm{AT}$ 시간이 경과함에
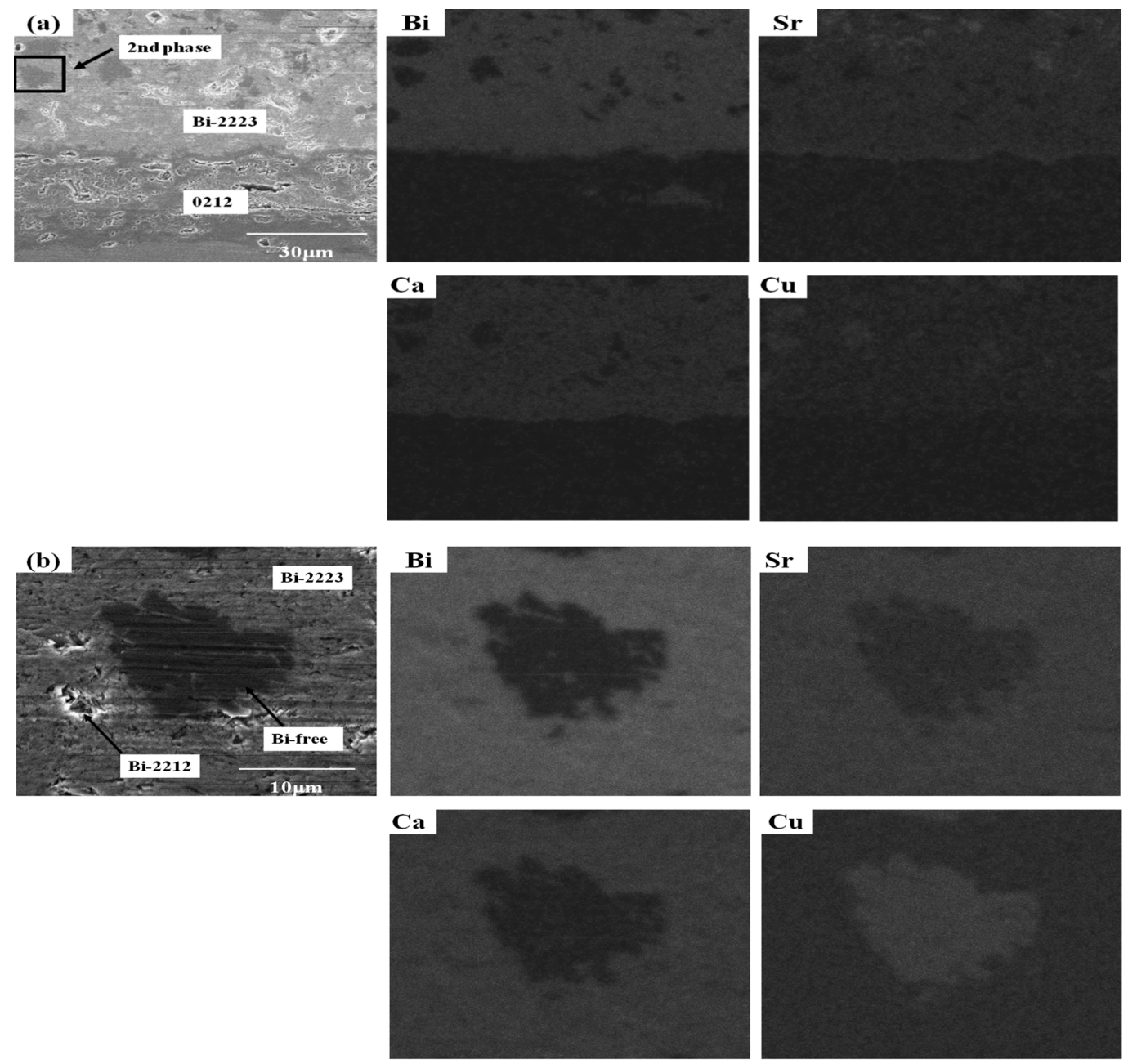

Fig. 4. SEM micrographs for cross-section of the Bi-2212/2223 phase(a) and 2nd phase(b) after AT(20h). 

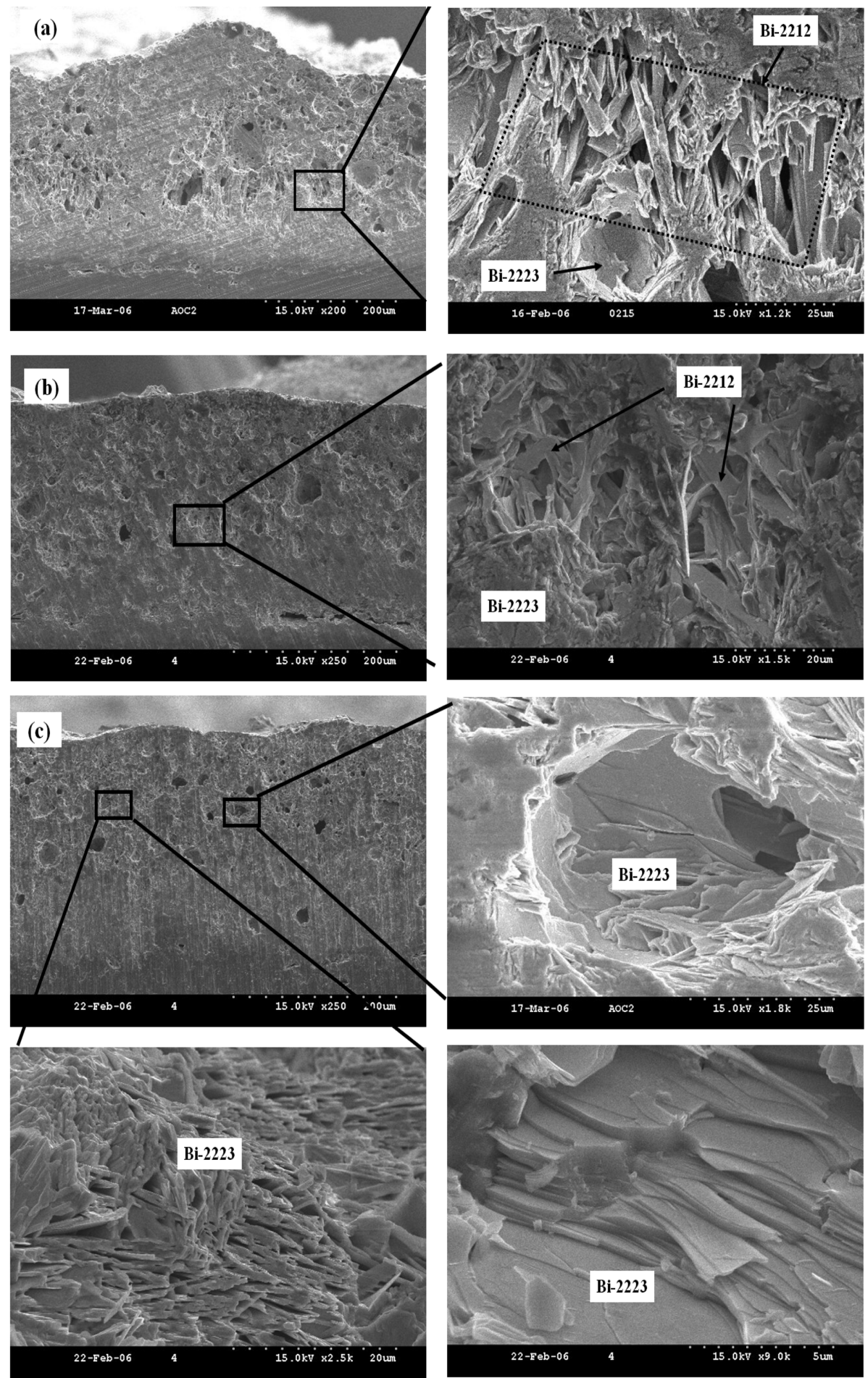

Fig. 5. SEM image of the Bi-2212/2223 micro-structures as AT time. (a) $10 \mathrm{~h}$, (b) $15 \mathrm{~h}$ and (c) $20 \mathrm{~h}$.

따라 그 형상이 변했다. 그림 (a)와 (b)에서 알 수 있듯 이 AT 시간이 10 시간에서 15 시간으로 증가함에 따라 불 규칙한 $\mathrm{Bi}-2212$ 상 휘스커의 길이는 점차 감소하게 되고 그림 (c)와 같이 AT 20시간에서는 $\mathrm{Bi}-2212$ 상 휘스커는 거의 없고 대부분 전형적인 판상 조직인 $\mathrm{Bi}-2223$ 상이 생 성되어있음을 알 수 있다.
Fig. 6은 Fig. 3의 조직에서 분리된 중간층을, Fig. 7 은 상층 및 하층의 XRD 결과를 나타냈다. 여기서 Fig. 3 에 표시된 것과 같이 중간층은 $\mathrm{Bi}-2212$ 상과 제 2상, 상 층과 하층은 $\mathrm{Bi}-2223$ 상과 제 2상으로 되어있음을 알 수 있다. 용사 코팅층의 이러한 제 2 상의 생성은 포정반응 이 완전히 이루어지지 못했기 때문이다. 


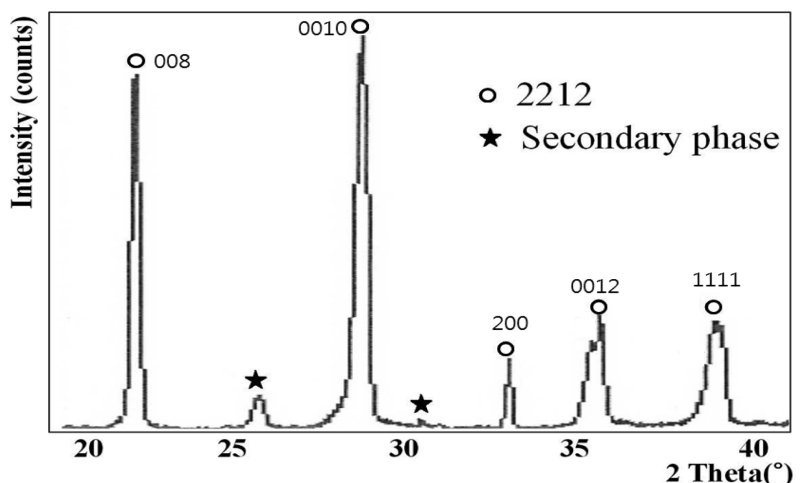

Fig. 6. X-ray diffraction patterns of Bi-2212 layer.

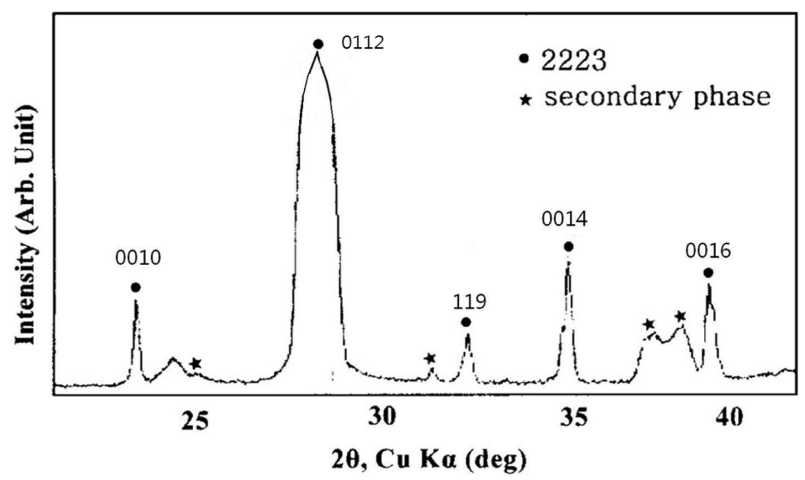

Fig. 7. X-ray diffraction patterns of Bi-2223 layer.

Fig. 8은 Fig. 2의 AT시간이 15시간, 20 시간 인 경우 의 초전도체 중앙부의 $\mathrm{XRD}$ 결과이다. 여기서 초전도 층 의 $\mathrm{Bi}-2212$ 상과 $\mathrm{Bi}-2223$ 상의 분율을 다음과 같은 식으로 구했다.

$$
\begin{aligned}
& \mathrm{V}_{2223}=\mathrm{I}_{2223}(0010) /\left(\mathrm{I}_{2223}(0010)+\mathrm{I}_{2212}(008)\right) \\
& \mathrm{V}_{2212}=\mathrm{I}_{2212}(008) /\left(\mathrm{I}_{2223}(0010)+\mathrm{I}_{2212}(008)\right)
\end{aligned}
$$

식에서 $\mathrm{I}_{2212}(008)$ 와 $\mathrm{I}_{2223}(0010)$ 는 $\mathrm{XRD}$ 결과 각각 $\mathrm{Bi}-$ 2212상과 Bi-2223상의 (008), (0010)면의 피크 강도이다.

Fig. 9는 AT 시간에 따른 $\mathrm{Bi}-2212$ 상과 $\mathrm{Bi}-2223$ 상의 분 율을 그림 3 의 $\mathrm{AT} 5$ 시간과 10 시간의 조직 분율과 그림7 의 XRD 분율 결과로부터 나타낸 것이다. 여기서 최초 $\mathrm{AT} 5$ 시간에서는 $\mathrm{Bi}-2212$ 상과 $\mathrm{Bi}-2223$ 상이 각각 $53 \%$, $47 \%$ 를 나타내며 이 후 AT 시간이 증가하면 $\mathrm{Bi}-2212$ 상 은 급격히 감소하다가 서서히 감소하는 반면 $\mathrm{Bi}-2223$ 상 은 급격히 증가하다가 서서히 증가한다. 이는 $\mathrm{AT}$ 시간이 경과함에 따라 최초 $\mathrm{Bi}-2212$ 상이 빠른 시간 내에 먼저 생 성되고 이후 확산에 의해 $\mathrm{Bi}-2212$ 상에서 $\mathrm{Bi}-2223$ 상이 생 성되는 현상으로 판단된다.

\section{2 용사 층의 초전도 특성}

Fig. 10은 코팅층을 PMP한 후 AT 시간 5시간과 20
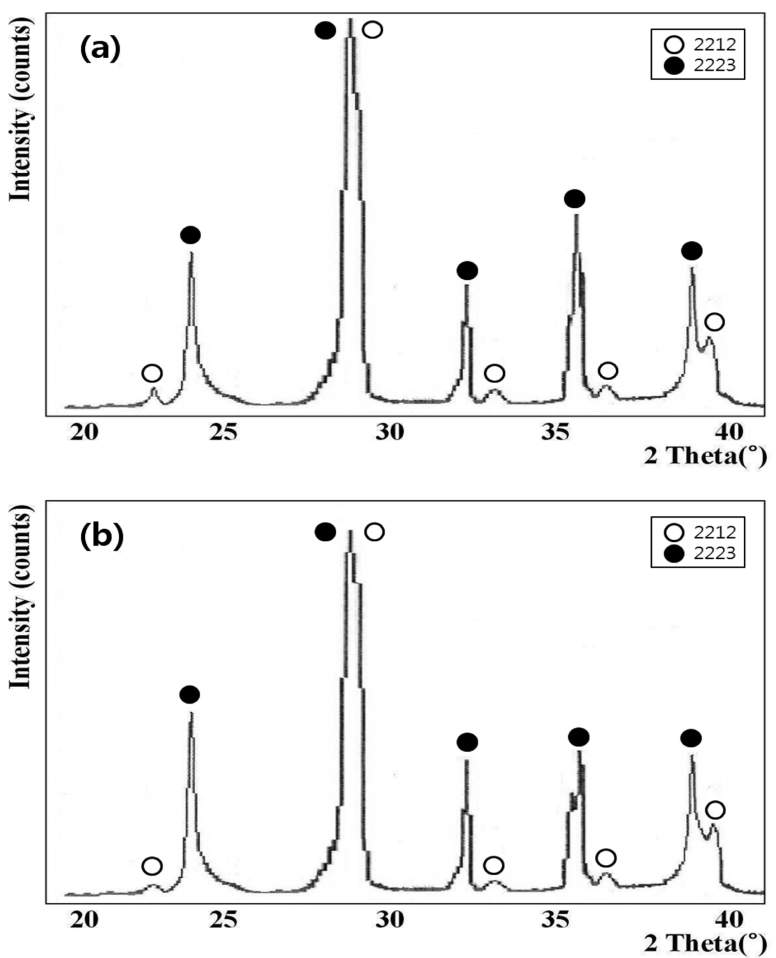

Fig. 8. X-ray diffraction patterns of the Bi-2212/2223 at various AT times. (a) $15 \mathrm{~h}$ and (b) $20 \mathrm{~h}$

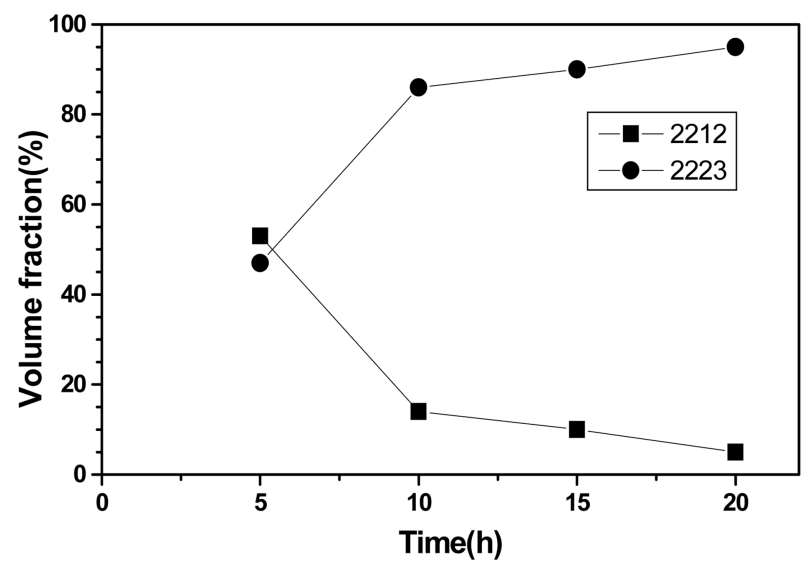

Fig. 9. Bi-2223 and Bi-2212 phase volume fraction on according to AT time.

시간에 대한 자기 모멘트의 변화이다. 먼저 AT 5시간에 서는 Fig. $10(\mathrm{a})$ 와 같이 $\mathrm{ZFC}(0 \mathrm{Oe})$ 에서 약 $50 \mathrm{~K}$ 와 115 $\mathrm{K}$ 의 임계온도를 보이고 있다. ${ }^{9}$ 즉 step 1 에서는 $\mathrm{Bi}-$ 2223 상에 의해 $115 \mathrm{~K}$ 부근에서 임계온도를 보이며 step 2 에서는 $50 \mathrm{~K}$ 부근에서 $\mathrm{Bi}-2212$ 상에 의해 임계온도를 보 이고 있다. 그러나 Fig. 10(b)와 같이 AT 20시간에서는 $115 \mathrm{~K}$ 부근에서만 임계온도를 보이고 있다. 이것은 앞서 미세조직 관찰에서 나타난 바와 같이 $\mathrm{AT}$ 20시간에 $\mathrm{Bi}-$ 2212상이 거의 소멸되고 대부분 $\mathrm{Bi}-2223$ 상이 형성되었기 때문으로 사료된다. 

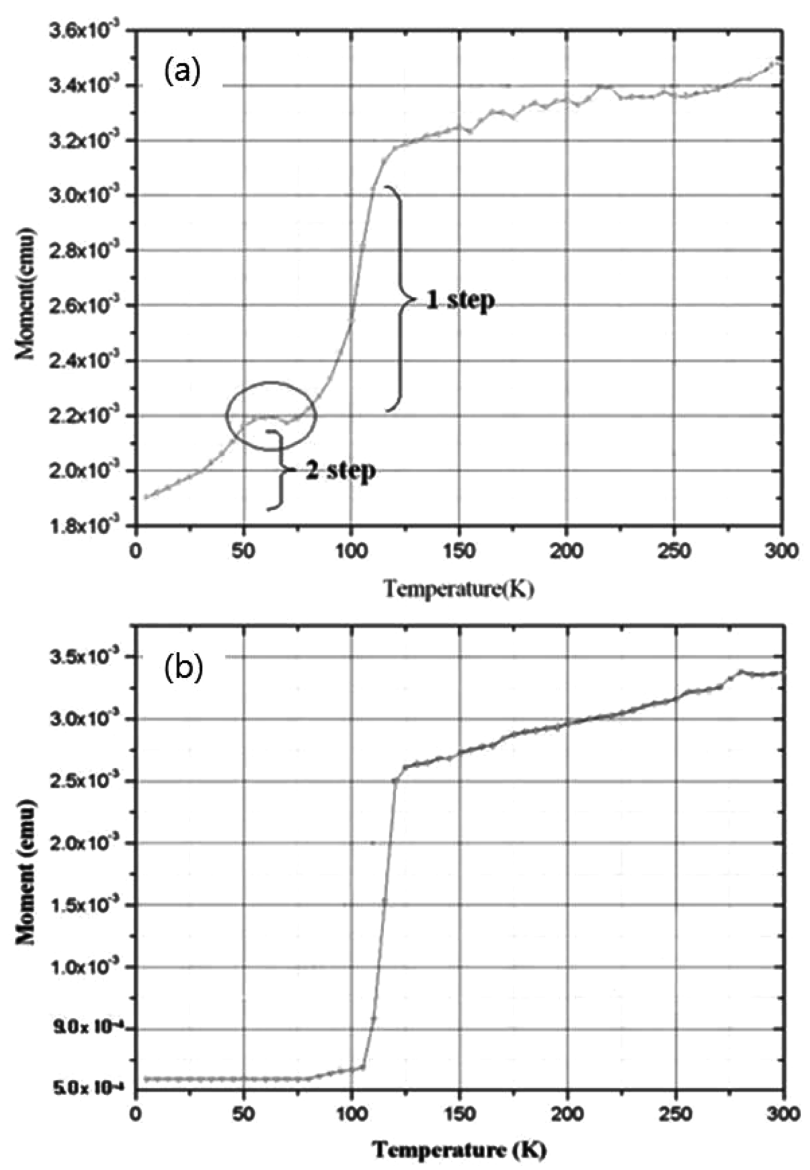

Fig. 10. The ZFC(0 Oe) magnetic moment of the $\mathrm{Bi}-2212 / 2223$ coatings as AT times. (a) $5 \mathrm{~h}$ and (b) $20 \mathrm{~h}$.

\section{4. 결 론}

본 연구에서는 2001 및 0212의 비율을 가지는 복합 용사 분말을 볼 밀링 방법으로 제조하여 0212/2001층을 용사하여 코팅층을 만들었다. 이것을 PMP 후 AT 시간 에 따른 $\mathrm{Bi}-2212 / 2223$ 초전도피막을 제조하였다. 이리하 여 초전도 코팅 층의 미세조직, 초전도 특성을 검토한
결과 다음과 같은 결론을 얻었다.

PMP-AT 5시간의 경우 2001 코팅 층과 0212 코팅 층 간에 불규칙한 $\mathrm{Bi}-2212$ 층이 형성되었고, 전형적인 침상 형태를 띤 미세한 결정립으로 되어있다.

$\mathrm{AT}$ 시간이 증가함에 따라 $\mathrm{Bi}-2212$ 상은 감소하고 $\mathrm{Bi}-$ 2223상은 증가하여 AT 20시간이면 Bi-2212상은 거의 소 멸되고 전형적인 판상조직인 $\mathrm{Bi}-2223$ 상이 대부분 생성되 었다.

AT 5시간일 경우는 $\mathrm{Bi}-2212$ 상과 $\mathrm{Bi}-2223$ 상의 공존으 로 $\mathrm{ZFC}$ 에서 초전도 임계온도가 각각 $50 \mathrm{~K}, 115 \mathrm{~K}$ 에서 나 타났다. 그러나 AT 20시간의 경우 $\mathrm{Bi}-2212$ 상이 거의 소 멸되고 대부분 $\mathrm{Bi}-2223$ 상이 형성되면서 임계온도가 $115 \mathrm{~K}$ 에서만 나타났다.

\section{References}

1. R. Inoue, H. Kitano, T. Hanaguri and A. Maeda, Adv. Superconductivity, 11(1), 121 (1998).

2. H. Nadifi, A. Ouali, C. Grigorescu, H. Faqir, O. Monnereau, L. Tortet, G. Vacquier and C. Boulesteix, Supercond. Sci. Technol., 13(8), 1174 (2000).

3. M. D. Sumption, X. Peng, E. Lee, F. Buta, M. Tomsic and E. W. Col 1 ings, IEEE Trans. Appl. Supercond., 13(3), 3486 (2003).

4. Y. Feng, Y. Zhao, A. K. Pradhan, L. Zhou, P. X. Zhang, X. H. Liu, P. Ji, S. J. Du, C. F. Liu and Y. Wu, Supercond. Sci. Technol., 15(1), 12 (2002).

5. Y. Yamada, F. Yamashita, K. Wada and K. Tachikawa, J. Jpn. Inst. Matals. 61(9), 836 (1997).

6. V. V. Pankov and P. Strobel, Physica C, Superconductivity, 235-240(1), 333 (1994).

7. A. Y. Ilyushechkin, T. Yamashita, L. Boskovic and I. Mackinnon, Supercond. Sci. Technol., 17(10), 1201 (2002)

8. A. Y. Ilyushechkin, T. Yamashita and I. Mackinnon, Physica C 377(3), 362 (2002).

9. S. H. Cho, S. H. Lee and K. C. Park, J. Kor. Int. Met. Mater., 44(7), 497 (2006). 